\title{
TECNOLOGIAS DE INFORMAÇÃO E COMUNICAÇÃO (TICS) E TRABALHO DOCENTE: desafio pedagógico
}

\author{
Pierre André Garcia Pires* \\ Liziany Lopes da Silva**
}

\begin{abstract}
Resumo: $\mathrm{O}$ presente trabalho tem como objetivo geral analisar os desafios pedagógicos frente às tecnologias de informação e comunicação. Também apresenta como objetivos específicos situar o leitor nas mudanças organizacionais da sociedade, da educação e das tecnologias, fazendo uma análise sobre a mediação pedagógica e o uso das tecnologias; por fim, verificar os impactos da informatização das escolas. A metodologia utilizada nesse artigo foi a bibliográfica e empírica. A educação na forma institucionalizada assumiu grandes responsabilidades com o tempo, que além de ser a responsável por transmitir os conhecimentos produzidos socialmente, elas têm uma responsabilidade social profunda. Educadores precisam, para garantir que essa educação atenda as exigências de qualidade vigente, compreender seu contexto histórico-social, econômico e ideológico; aos professores entender sua responsabilidade como mediador pedagógico, ter bem estabelecido suas metodologias no uso das tecnologias de informação e comunicação, além de discutir a importãncia da formação continuada para o processo educacional. Assim, as discussões realizadas neste trabalho estão embasadas em Frigotto (2006), Moran (2015), Lima e Moura (2015), Heller (2004), Meirieu (2005), Moran, Macetto e Behens (2007).
\end{abstract}

Palavras-chave: Tecnologias de informação e comunicação; Mediação pedagógica; Formação Docente.

\section{INFORMATION AND COMMUNICATION TECHNOLOGIES (ICTS) AND TEACHING WORK: A pedagogical challenge}

\begin{abstract}
The general purpose of this work is to provide an assessment on pedagogical challenges when facing information and communication technologies. Also, as specific goals, this work places the reader inside organizational changes of the society, the education and technologies, by making an analysis about the pedagogic intercession and the use of technologies; lastly, to evaluate impacts of computerization in the schools. The methodologies applied in this article were bibliographical and empirical. The education, in its instituted shape, has taken greater responsibilities with time, since besides being in charge of transferring socially-produced knowledge, it has a deeper social responsibility. In order to ensure the education complies with current quality requirements, the educators need to understand its social-historical, economic and ideological context, having the teachers an understanding of their responsibilities as pedagogic mediators, and well established their methodologies in the use of information and communication technologies, besides discussing the relevance of continuous formation to the education process. Therefore, the discussions made in this work are based on the work of Frigotto (2006), Moran (2015), Lima e Moura (2015), Heller (2004), Meirieu (2005), Moran, Macetto and Behens (2007).
\end{abstract}

Keywords: Information and communication technologies; Pedagogic mediation; Teaching formation.

Submissão 20-10-18 Aceite 10-04-19

\section{INTRODUÇÃO}

Vivemos constantemente em espaços que nos remetem a coisas que normalmente estamos habituados, seja no ambiente de trabalho, com amigos ou na própria família, até mesmo o que vemos na internet, por exemplo, são coisas que

\footnotetext{
* Professor Adjunto III da Universidade Federal do Acre/UFAC. Programa de Pós-graduação, Mestrado Profissional em Ensino de Ciências e Matemática- MPECIM. Líder do Grupo de Pesquisa em Educação e Cultura. Professor da área de Didática e Investigação e Prática Pedagógica. Doutor em Educação pela Universidade Federal do Paraná/UFPR, Mestre em Educação Ambiental pela Universidade Federal do Rio Grande/FURG.

${ }^{* *}$ Professora do Instituto Federal do Acre- IFAC, Campus Cruzeiro do Sul/AC Mestra em Ensino de Ciências e Matemática, pelo Programa de Mestrado Profissional em Ensino de Ciências e Matemática pela Universidade Federal do Acre/UFAC.
} 
comumente nos interessam. O ponto delicado dessa situação é de não se buscar coisas diferentes, não compreender que o cotidiano é cheio de possibilidades, perder a capacidade de aprender com as próprias experiências. Estamos reduzindo nossas percepções, nossos sentidos e nos esquecendo que no diferente está a beleza, pois nos desperta a curiosidade.

Apesar da cotidianidade trazer a ideia de cada dia ser diferente, somos constantemente reduzidos a pensar ou agir conforme um padrão, aceito pela maioria, nos impedindo novas aprendizagens. Somos tendenciados a não formular nossas próprias percepções, a gente parte de percepções pré-formuladas para criar nossos julgamentos. Todo mundo fica no óbvio por medo de errar. Mas é preciso saber que a observação é fundamental, sempre aprendemos sobre o mundo a partir de visões pré-estabelecidas.

Quando se fala em homem da cotidianidade, sabe-se que este ao mesmo tempo em que é ativo em seu meio é também receptivo desse meio (HELLER, 2004) o que não significa que este absorva inteiramente todos os aspectos existentes e nem em sua total intensidade. Pode-se afirmar que a cotidianidade é heterogênea, pois somos diferentes em diferentes situações e ressignificamos nossa prática constantemente. Ao se falar em heterogeneidade, fala-se tanto em conteúdo quanto em significação de nossos tipos de atividade. Essas significações mudam com o tempo e com as experiências vivenciadas.

Nascemos inseridos na cotidianidade, mas não podemos esquecer da individualidade do homem que funciona consciente e inconscientemente (HELLER, 2004). Nos tornamos conscientes de nossa individualidade e de nossa genericidade. Enquanto indivíduos, somos livres e temos várias possibilidades de liberdade, mas não nos esquecendo que existem normas da ética que faz com que submetamos nossa particularidade ao genérico. O desafio é transformar essa ética em motivação, o que alguns autores chamam de moral, que é algo individual, isto é, adotada livremente por nós, mas não de motivação particular.

Uma das funções da moral é a inibição, o veto, a outra é a transformação, a culturalização das aspirações da particularidade individual. A moral, nesse contexto, assume grande importância tendo como consequência que quanto maior a importância da moralidade, mais facilmente essa decisão eleva-se acima da cotidianidade e tanto menos se pode falar de uma decisão cotidiana.

A escola tem grande importância para a sociedade, pois assume grandes responsabilidades, desde o acúmulo de saberes historicamente construídos até a construção 
de novos conhecimentos. Ela sofre constantes mudanças, de acordo com as transformações sociais. Nos últimos tempos, as tecnologias da informação e comunicação trouxeram significativas modificações na estrutura social, de trabalho e, concomitantemente, na educação. Mas vale a pena analisar até onde a escola se permite refletir e adentrar no contexto social vigente? Até que ponto está o comprometimento profissional dos educadores e como se encontra o contexto em sala de aula frente à essas novas demandas apresentadas?

Diante a problemática do modelo educacional vigente encontrar dificuldades em formar sujeitos aptos a se relacionar com as mudanças de crenças, valores e formas de trabalho que as tecnologias da informação e comunicação proporcionam, propõe-se, nesse artigo, uma análise dos desafios educacionais frente a essas tecnologias, primeiramente situando o leitor nas mudanças organizacionais da sociedade, da educação e das tecnologias, depois fazendo uma análise sobre a mediação pedagógica e o uso das tecnologias, e por fim, verificando os impactos da informatização das escolas.

\section{O COTIDIANO DA ESCOLA E O CONTEXTO DA SALA DE AULA}

Será feita uma relação entre o posicionamento de Meirieu (2005) sobre o cotidiano da escola e da sala de aula com a questão do uso das Tecnologias da Informação e Comunicação (TICs). O autor nos apresenta alguns princípios para uma instituição escolar, primeiramente trazendo alguns conceitos de princípios, apresentados etimologicamente, filosoficamente e em um sentido mais polêmico. Respectivamente, o princípio está relacionado com a origem no seu sentido ideal; está relacionado, também, a essência no sentido de compreender a realidade e a relevância de algo; e por fim, e num sentido mais polêmico, o princípio remete a uma ordem, sendo necessário ignorar as adversidades que impedem sua finalidade.

Partindo para os princípios, (i) a escola não é apenas um serviço Meirieu (2005), mas uma instituição, em breves palavras, não se trata apenas de satisfazer um público alvo, mas por ser uma instituição única, possui características particulares que precisam ser levadas em consideração. As tecnologias da informação e comunicação trouxeram muitas mudanças na sociedade, não deixando de ser diferente dentro da instituição escolar, mas se a escola não compreende sua finalidade dentro desse contexto inovador de tecnologias, a inserção das TICs não fará muita diferença, pois se a escola adota as mesmas posturas, utilizando as mesmas metodologias de muito tempo, 
num contexto histórico-social diferente, não compreendendo qual sua finalidade real enquanto instituição, não fará muita diferença na vida do indivíduo e na sociedade. Dessa forma Moran (2017), vem destacar a partir deste contexto "o ensino híbrido", onde todos os envolvidos no processo de construção de saberes "são aprendizes e mestres, consumidores e produtores de informação e de conhecimento" (MORAN, 2017, p. 28).

$\mathrm{Na}$ educação, acontecem vários tipos de mistura, blended ou educação híbrida: de saberes e valores, quando integramos várias áreas de conhecimentos (no modelo disciplinar ou não); de metodologias, com desafios, atividades, projetos, games, grupais e individuais, colaborativos e personalizados. Também falamos de tecnologias híbridas, que integram as atividades de sala de aula com as digitais, as presenciais com as virtuais. Híbrido também pode ser um currículo mais flexível, que planeje o que é básico e fundamental para atender às necessidades de cada aluno. Híbrido também é a articulação de processos de ensino e aprendizagem mais formais com aqueles informais de educação aberta e em rede. Implica misturar e integrar áreas, profissionais e alunos diferentes, em espaços e tempos distintos. (MORAN, 2017, p. 28-29).

Em uma democracia, os princípios que fundamentam a Escola só podem ser encontrados nas (ii) próprias condições que possibilitam o exercício democrático Meirieu (2005), ou seja, em uma democracia, os princípios fundamentais são as condições que tornam a democracia possível. É necessário observar, também, que a instituição escolar só existe hoje se os atores incorporarem no dia-a-dia os princípios que a inspiram, o professor possui sua subjetividade e a escola surge como lugar de reconstrução. Se os sujeitos da escola não compreendem esse princípio, não conseguirão cumprir sua função social enquanto educador. Essa democracia deve ser exercida desde a sala de aula até os lugares mais amplos da escola. Se sabemos desse princípio, por que há, segundo a literatura, grande rejeição quanto a inserção das TICs e de novas metodologias de aprendizagem? Por que continuamos adotando posturas extremamente tradicionais que impedem o exercício da democracia e consequentemente da aprendizagem?

A missão fundamental da escola é (iii) transmitir às jovens gerações os meios de assegurar, ao mesmo tempo, seu futuro e o futuro do mundo Meirieu (2005), ao mesmo tempo em que precisa "formar" sujeitos para a sociedade, deve dar ferramentas para este sujeito modificar e/ou melhorar uma determinada realidade. Conforme as mudanças sociais historicamente construídas, a escola assume grandes responsabilidades, começa a ser vista e almejada por determinados grupos sociais, 
quando compreendem a importância dessa instituição e o impacto que as decisões e posturas nela adotadas têm na sociedade de modo geral, tornando-se alvo de grandes interesses, não significando que estes venham a atender uma maioria, embora cada vez mais se lute por uma escola de boa qualidade para todos, assim:

Cada aluno desenvolve um percurso mais individual e participa em determinados momentos de atividades de grupo. Nos cursos on-line, uma parte da orientação será via sistema (plataformas adaptativas com roteiros semiestruturados, que respondem as questões mais previsíveis), e a principal será feita por professores e tutores especialistas, que orientarão os alunos, nas questões mais difíceis e profundas. (MORAN, 2017, p. 42).

A escola traz uma especificidade, onde se apresenta obrigatória (as coisas são organizadas para não sair de seu ambiente), progressiva (possibilidade de saber sem aprender) e exaustiva. A própria estrutura da escola traz em seu bojo essas características, desde sua organização de pessoas até a organização dos conteúdos. Pode-se afirmar também que (iv) a escola é institucionalizada, sistematizada e progressiva (crescente) Meirieu (2005). A história da Escola e da pedagogia testemunha a ambição dos homens de não excluir ninguém do processo de transmissão.

Com a compreensão da importância da Escola, houveram interesses por parte da maioria de ser um local em que todos têm direito ao seu acesso, já que as estruturas sociais ficaram mais complexas, surgindo a necessidade de um ambiente em que se responsabilizasse pela transmissão dos conhecimentos historicamente construídos, que até então era privilégio de poucos, mas que tornou-se essencial para todos os sujeitos. Assim, na medida em que é conduzida por um objetivo de universalidade, a Escola se define não como um espaço privado, mas público, também não é compatível com a busca de nenhum tipo de homogeneidade, seja ideológica, sociológica, psicológica ou intelectual, sendo necessário que seus sujeitos compreendam a heterogeneidade e ajam de acordo com ela:

Por isso é importante que cada instituição escolar defina um plano estratégico para tais mudanças A princípio, pode ser de forma mais pontual, apoiando professores, gestores e alunos - e também alguns pais - que estão mais motivados e têm experiências em integrar o presencial e o virtual. (MORAN, 2017, p. 43).

Além dessas questões, (v) a Escola precisa acabar com suas certezas e/ou verdades Meirieu (2005), abrindo portas para as diferentes perspectivas de conhecimento, acabando com as imposições à produção e aceitar que é sempre mais 
importante "compreender" do que "fazer", ou seja, muda-se assim a relação professor e aluno. A Escola precisa (vi) ser um espaço onde se possa errar sem risco Meirieu (2005) e precisa ser por si mesmo seu próprio recurso, libertando aqueles que a frequentam de todas as formas de ascendência sobre os espíritos e, por fim, deve conjugar integração, emancipação e promoção da humanidade no homem.

\section{MUDANÇAS ORGANIZACIONAIS, EDUCAÇÃO E TECNOLOGIAS}

A educação tem se apresentado, historicamente de maneiras diferentes, isto é, mudanças sociais exigem modificações na estrutura da escola desde questões mais objetivas, como por exemplo uma mudança em sua infraestrutura com o intuito de atender quesitos de acessibilidade, como questões subjetivas, por exemplo a relação ensino e aprendizagem. Uma mudança que merece menção é o surgimento da "teoria do capital humano" que traz à educação a responsabilidade de desenvolvimento econômico, estabelecendo assim, uma ligação entre educação e trabalho, além de considerar a educação funcional ao sistema capitalista.

Existe também uma ideia difundida por alguns educadores de que a educação possui um caráter improdutivo, como ressalta Frigotto (2006):

[...] a ideia básica é que assim como o capital no seu processo de acumulação, concentração e centralização pelo trabalho produtivo vai exigindo cada vez mais, contraditoriamente, trabalho improdutivo, como se fosse verso e anteverso de uma mesma medalha, a "improdutividade da escola" parece constituir, dentro desse processo, uma mediação necessária e produtiva para a manutenção das relações capitalistas de produção. A desqualificação da escola, então, não pode ser vista apenas como resultante das "falhas" dos recursos financeiros ou humanos, ou da incompetência, mas como uma decorrência do tipo de mediação que ela efetiva no interior do capitalismo monopolista. (FRIGOTTO, 2006, p. 134).

Mediante as duas proposições abordadas anteriormente, educadores têm se dividido em acreditar na educação com ou sem alusão à formação profissional, ou acreditando numa formação dualista com formação geral desligada da formação profissionalizante.

É verdade que a educação formal surge a partir da necessidade social, onde mudam-se as estruturas de trabalho e organização da sociedade, surgindo assim a escola, local, a priori, de transmissão de saberes e de construção de conhecimentos, que até o momento era feito através de outros aparelhos ideológicos do estado, 
com convivência na família e na igreja. Consequentemente, no período de ascensão das indústrias e das cidades, verifica-se que sendo a indústria a base do desenvolvimento das cidades, o campo se subordina à ela, passando a ser controlado por relações do tipo urbanas. A sociedade deixa de ser natural para ser dominantemente social, trazendo em seu bojo a estratificação de classes.

Uma sociedade com essas características traz consigo a premissa de generalização da escola. Nesse período da Época Moderna, havia uma tentativa constante de subordinar a natureza aos propósitos do homem, e a ciência e/ou conhecimento se apresenta como poder material, no processo produtivo, onde, como estudiosos afirmam, conhecimento é poder (FOUCAULT, 1979, 2010, 2013). As relações da educação com a sociedade se modificam consequentemente, como afirma Saviani (2013):

Quanto mais avança o processo urbano-industrial, mais se desloca a exigência da expansão escolar. Por aí é possível compreender exatamente por que essa sociedade moderna e burguesa levanta a bandeira da escolarização universal, gratuita, obrigatória e leiga. A escolaridade básica deve ser estendida a todos. (SAVIANI, 2013, p. 156).

A escola tem íntima ligação com o desenvolvimento da sociedade e surge como principal instrumento de educação, sendo as demais formas tidas como secundárias e compreendidas a partir da escola. Diante desse cenário, tem-se a escola assumindo responsabilidades que eram atribuições da família. A cada momento, a escola tem assumido responsabilidades maiores em educação, e cada vez mais o indivíduo entra com menos idade e passa mais tempo dentro da escola, assim, está sendo atribuído à escola tudo aquilo que é educativo, além de uma exigência que extrapola o pedagógico.

Contrário a isso, há estudiosos que compreendem a escola como um espaço secundário, onde a sociedade e o trabalho estão intimamente relacionados com o processo educacional do sujeito, mas destes, há aqueles que atribuem maior peso à escola. Frente a esse contexto histórico é possível observar que ao mesmo tempo em que se tenta generalizar a escola, presencia-se uma diferença entre escolas da elite e escolas para as massas, respectivamente, uma destinada à formação intelectual e a outra à formação técnica. Mas ao se reivindicar uma educação universal, gratuita e obrigatória, coloca-se em "cheque" muitas questões historicamente construídas no âmbito escolar.

Com a universalização da escola primária, os sujeitos já aprendem a se relacionar com as posturas e características da sociedade moderna, onde há uma divisão 
clara dos conhecimentos gerais (qualificação intelectual) e específicos (qualificação profissionalizante). Surge assim, como mote de pesquisas atuais a análise da introdução das novas tecnologias.

A sociedade em geral, vive um momento diferente em que as tecnologias estão cada vez mais se desenvolvendo, modificando as relações sociais, de trabalho e educacionais. Exige-se maior qualificação intelectual, para não apenas manusear essas tecnologias, mas também saber como funcionam, quais melhores estratégias para utilizá-las para fins determinados e outros. A escola entra nesse contexto como uma instituição responsável por desenvolver as potencialidades dos sujeitos para viver e conviver com as tecnologias, e exige-se cada vez mais uma melhor qualidade no desenvolvimento da totalidade dos sujeitos. Embora a escola ainda tenha em seu bojo questões de interesses de uma parcela da sociedade mais favorecida em detrimento de uma menos favorecida, ela vive uma dicotomia, onde além de perpetuar posturas, normas, cultura e outros, ela também busca modificar a realidade em que a sociedade vive, desenvolvendo sujeitos críticos e participantes desta.

Mesmo vivenciando um período de produção automatizada, o homem continua sendo aquele que manipula, controla ou organiza as tecnologias. Sendo assim, o trabalho continuará sendo a base do sistema educativo. Comparando o desenvolvimento social, embora o Brasil esteja atrasado em relação a outros países no quesito tecnologias, é perceptível o quanto a escola está atrasada em relação as novas exigências que estão sendo postas pela sociedade.

\section{MEDICAÇÃO PEDAGÓGICA E O USO DA TECNOLOGIA}

Uma das discussões que permeiam a educação está na inserção das tecnologias no contexto escolar, visto que a escola ainda perpetua posturas de uma pedagogia tradicional valorizando as aulas expositivas, conteudista e avalições que acentuam a memorização. Desconsidera-se dessa forma, um processo de ensino-aprendizagem mais eficaz e mais próximo da realidade histórico-social do aluno. Essas posturas tradicionais ainda são disseminadas inclusive nos cursos de formação docente, mas vale refletir quais são as contribuições da inserção das tecnologias dentro da escola e para a formação desses novos profissionais em educação. É preciso compreender quais os motivos que podem contribuir para a não valorização da inserção e uso das tecnologias na educação. Conforme Moran, Macetto e Behrens (2007): 
[...] Percebe-se por parte dos alunos a valorização de conteúdos nas áreas específicas em detrimento das disciplinas pedagógicas. Alunos e, por vezes, professores dos cursos de história, geografia, matemática, física, ciências, biologia, sociologia e outros afirmam, sem constrangimento, que o importante para se formar professor é o domínio dos conteúdos dos respectivos cursos. Cursar disciplinas pedagógicas é obrigação para se ter diploma de licenciado e poder exercer o magistério, no entanto, nenhum valor se agrega à competência para a docência. (MORAN; MACETTO; BEHRENS, 2007, p. 134-135).

Além da desvalorização nas disciplinas pedagógicas por parte dos alunos de graduação de licenciatura, percebe-se que os professores da graduação pouco utilizam as tecnologias, consequente a isto, os futuros profissionais em educação têm uma forte inclinação a repetir posturas didáticas de seus professores, sem a devida compreensão da metodologia que está sendo utilizada e nem sobre os objetivos e consequências de uma avaliação. Outro motivo possível da desvalorização da tecnologia em educação, foi a imposição do uso das técnicas nas escolas, nos anos 1950 e 1960, baseando-se na teoria comportamentalista:

[...] ao mesmo tempo em que defendiam a autoaprendizagem e o ritmo próprio de cada aluno nesse processo, impunham excessivo rigor e tecnicismo para se construir um plano de ensino, definir objetivos de acordo com determinadas taxonomias, implantar a instrução programada, a estandardização de métodos de trabalho para o professor e de comportamentos esperados dos alunos. (MORAN; MACETTO; BEHRENS, 2007, p. 135).

Ao se falar em melhoria da qualidade da escola, há muita rejeição por parte dos educadores, seja por lembrar desse período do tecnicismo ou mesmo pela ideia da Qualidade Total que foi assimilada pela escola, assumindo posturas e estratégias de empresas, mesmo a escola sendo um lugar com um fim diferente, possuindo algumas semelhanças estruturais, mas além disso, com características bem particulares, próprias da escola.

Em meio a todas essas questões, se faz necessário refletir e buscar novas formas de educar, com metodologias bem planejadas e que motivem os alunos, ter objetivos educacionais bem estabelecidos para se alcançar a aprendizagem, saber avaliar todo o processo de ensino-aprendizagem, rever questões de relação professor-aluno e outros. Continuar com posturas educacionais tradicionais, não aceitar metodologias e/ou estratégias eficientes, não abrir portas para as tecnologias na educação, revela o descompromisso dos educadores com o ensino-aprendizagem.

Esse novo momento social traz à tona várias discussões em torno de assuntos como, a utilização das tecnologias no contexto escolar, além das metodologias aplicadas 
ao ensino, a visão moderna de conhecimento científico, questões como comunicação e informação no mundo globalizado, a curiosidade no ensino, posturas didáticasmetodológicas inclusivas, avaliação, as relações educação, sociedade e trabalho, além de outros temas. Provoca também, especificamente, um debate quanto ao uso dessas tecnologias, do papel do professor e mediação pedagógica. Outra discussão importante é sobre a formação inicial e continuada dos docentes, inclusive das competências didáticas do professor universitário. Existem profissionais que buscam, além de novas metodologias, refletir sobre seu papel enquanto professores, sua relação com os alunos em sala de aula, a questão da motivação e etc.

A tecnologia não é a solução para os problemas educacionais, é apenas um instrumento de aprendizagem, ou seja, só resultará em soluções positivas se aplicadas de forma eficaz e bem planejada. Ao refletir sobre tecnologia e educação, é interessante analisar alguns conceitos como ensinar e aprender, onde respectivamente, um faz alusão as posturas do professor e o outro ao aluno. O professor surge como um mediador entre o aluno e a aprendizagem, facilitando o acesso ao conhecimento e motivando os alunos, "o uso de tecnologias serve como combustível bastante diversificado de ferramentas que podem estimular e facilitar o processo de aprendizagem e cabe o professor ensinar ao aluno como utilizá-las de forma crítica e produtiva” (LIMA; MOURA, 2017, p. 91).

Há grande diferença entre o processo de ensino e o de aprendizagem, onde o primeiro é ativo e participante e não mais passivo e repetidor, como a pedagogia tradicional pregava, o segundo, assume papel de orientador, facilitador, mediador pedagógico. Essa postura nova traz ao professor muitas inseguranças, pois sai da zona de conforto, se coloca num lugar de contato direto com o aluno.

Vive-se ainda um momento em que o uso das tecnologias privilegia a técnica, usadas normalmente para transmitir informação, mas é preciso alterar esses usos, não somente utilizar a tecnologia como técnica, mas (re)pensar suas metodologias, como "uma forma de ensinar que mistura as melhores práticas da sala de aula tradicional com ferramentas digitais personalizadas ou ajustadas às finalidades pedagógicas” (LIMA, MOURA, 2017, p. 91). Percebe-se que as tecnologias, lentamente, têm entrado nas instituições educativas, mas a metodologia utilizada pelos professores ainda continua numa visão tradicional de ensino.

As técnicas precisam ser escolhidas de acordo com o que se pretende que os alunos aprendam. Como o processo de aprendizagem abrange o desenvolvimento intelectual, afetivo, o desenvolvimento de competências e atitudes, pode-se deduzir que a tecnologia a ser usada 
deverá ser variada e adequada a esses objetivos. Não podemos ter esperança de que uma ou duas técnicas, repetidas à exaustão, deem conta de incentivar e encaminhar toda a aprendizagem esperada. ((MORAN; MACETTO; BEHRENS, 2007, p. 143)

As metodologias adotadas pelo professor, devem condizer com o novo perfil de sujeito e com o novo perfil de sociedade e o próprio perfil de escola que precisa ser desenvolvido. Não apenas sendo aquele profissional que passa conteúdos aos seus alunos, mas sabendo e cumprindo sua responsabilidade social e educacional de acordo com o momento histórico-social vigente. Lembrando que a tecnologia só fará sentido se com ela for possível alcançar os objetivos de aprendizagem propostos.

O desafio diante o exposto é como a utilização das tecnologias em educação poderão desenvolver uma mediação pedagógica. Para essa compreensão, faz-se necessário a abordagem do conceito de mediação pedagógica, que, exposto claramente por Moran, Macetto e Behrens (2007), é “ A atitude, o comportamento do professor que se coloca como um facilitador, incentivador da aprendizagem, que se apresenta com a disposição de ser uma ponte entre o aprendiz e sua aprendizagem". Sendo assim, a mediação pedagógica acentua o papel de sujeito do aprendiz, assumindo sua responsabilidade no alcance dos objetivos educacionais, "essa mediação é uma habilidade pouco explorada na prática docente, e a tecnologia permite ao professor passar a instrução on-line e trabalhar propostas inovadoras em sala" (LIMA; MOURA, 2017, p. 94).

Há autores que discutem o termo "Novas Tecnologias" com opiniões variadas sobre o termo, mas será referido a ele neste texto, como o uso da informática, computador, internet, multimídia, outros. Essas novas tecnologias proporcionam um ambiente totalmente diferente do modelo tradicional de sala de aula, com som, imagem, além de uma comunicação rápida e mais acessível, claro se utilizada da forma ideal.

As chamadas novas tecnologias não devem ser utilizadas para substituir o papel do professor, nem como uma ferramenta apenas para uma educação a distância, mas como um instrumento que valorize a autoaprendizagem e formação permanente dos sujeitos, facilitando a aprendizagem. Alguns autores chamam a atenção para se trabalhar com essas tecnologias não como ferramentas otimizadas de passar conhecimento, mas estabelecendo situações problematizadoras como metodologia de ensino.

Em primeiro lugar, é preciso saber formular problemas. E, digam o que disserem, na vida cientifica os problemas não se formulam de modo espontâneo. É justamente esse sentido do problema que caracteriza o verdadeiro espírito científico. Para o espírito científico, todo 
conhecimento é resposta a uma pergunta. Se não há pergunta, não pode haver conhecimento científico. Nada é evidente. Nada é gratuito. Tudo é construído." (BACHELARD 1996, p. 148)

É preciso que o processo de ensino e aprendizagem faça sentido e tenha um significado para o aluno, mas para isso o professor precisa planejar as atividades estabelecendo objetivos de aprendizagem claros, além de verificar se aquela estratégia escolhida permitiu o alcance dos objetivos traçados, isto é, o professor precisa ter bem claro a compreensão de seu novo papel, de mediador pedagógico.

Para o professor ser um mediador pedagógico precisa adotar algumas posturas, como compreender que o aluno é o centro do processo educativo e que precisa planejar suas aulas em função da aprendizagem destes, que a aprendizagem depende da relação em conjunto entre professor e aluno, permitir a participação dos alunos no planejamento, execução e avaliação de atividades, considerar o aluno como adulto (em cursos de ensino superior), ter domínio de sua área de conhecimento, criatividade, disponibilidade para diálogo, compreender o caráter subjetivo e individual dele e dos alunos, e por fim, estabelecer estratégias de comunicação em função da aprendizagem.

As novas tecnologias, com relação ao sistema de produção vigente, vêm trazendo duas ideias antagônicas, onde ao mesmo tempo em que traz a ideia de melhores condições de trabalho, também exige maior especialização dos trabalhadores. Infelizmente avanço técnico não significa inclusão de todos na sociedade, diminuição de desemprego, melhor qualidade de ensino e outros, principalmente num país subdesenvolvido e com desigualdade social. Em educação, a inclusão digital não se faz facilmente, principalmente num país com uma taxa de analfabetismo funcional ainda elevada.

A ideia é entender as razões da inserção dessas tecnologias na escola, sem esquecer de analisar quais as relações que vão continuar com essas mudanças, por exemplo as desigualdades, refletindo sobre as intenções por trás desse avanço tecnológico para a sociedade, educação e trabalho, além das mudanças que trará no trabalho docente. Para uma reflexão do trabalho docente que atenda as exigências atuais desse modelo econômico, social e ideológico, é preciso além de ter em mente quais resultados educacionais ideais se buscam antes mesmo de iniciar um planejamento, considerar questões mais específicas como valorização profissional, tempo de trabalho, quantidade de alunos, condições materiais de trabalho, conteúdos a serem ministrados, etc., ou seja, uma ampla análise do trabalho docente.

Os Parâmetros Curriculares Nacionais (PCN, 1998) e a Lei de Diretrizes e Bases (LDB, 1996) apontam a importância da formação continuada por parte dos educadores, 
compreendendo que esta formação significa uma formação complementar, de atualização de conhecimentos, repensar sua prática frente as necessidades sociais. Mas é preciso, para além disso, adotar medidas que garantam os direitos profissionais destes educadores e refletir sobre a questão de estas tecnologias estarem realmente a serviço do coletivo.

\section{CONSIDERAÇÕES FINAIS}

Ao abordar o tema sobre a relação da educação com a informática, é preciso ter em mente que não se refere apenas ao professor entrar em contato e saber usar a tecnologia, mas sim compreender como essas tecnologias podem facilitar o processo de ensino-aprendizagem. Para isso, o professor precisa estar constantemente se atualizando e buscando embasamento teórico para sua prática. A formação continuada desses profissionais é fundamental para a melhoria da qualidade educacional, visto que a sociedade sofre constantes mudanças.

As tecnologias de informação e comunicação adentram o cotidiano dos sujeitos, embora a maioria ainda não domine sua linguagem e não compreenda ainda como questioná-la. A educação precisa se apropriar dessas ferramentas pois deve acompanhar ou atender as necessidades sociais e econômicas do sistema capitalista. Surge a necessidade de os professores estimularem nos alunos posturas criativas, dar condições para eles construírem conhecimentos e serem sujeitos que desenvolvam soluções tecnológicas para melhorar a condição de vida das pessoas.

A sociedade vive um momento de busca, na educação, de formas de melhorar sua qualidade de vida social e econômica, entendendo sua responsabilidade nesse processo. Em educação se discute cada vez mais a melhor qualidade desta e sua adequação as exigências atuais de trabalho. Por isso é preciso entender o contexto histórico-social que provocou determinadas mudanças educacionais, entender o que há por trás dessas mudanças relacionando-as com a estrutura econômica, social e ideológica, compreendendo a importância do conhecimento na vida das pessoas.

A escola possui uma responsabilidade social de garantir acesso aos conhecimentos construídos por seus sujeitos e relacionar com sua realidade, mas para que isso se efetive precisa haver um comprometimento por parte dos educadores em proporcionar de fato $\mathrm{o}$ conhecimento. Os desafios da profissão docente são muitos, principalmente num contexto de novas tecnologias onde a estrutura social está tão diferente. $\mathrm{O}$ professor entendendo 
seu contexto, sua responsabilidade profissional de mediador pedagógico, os usos corretos dessas tecnologias para que realmente o ensino-aprendizagem aconteça, entendendo as metodologias por ele utilizada, que discutir sua formação em sentido amplo, estará, em grande parte, melhorando seus conhecimentos e sua prática profissional, além de estar contribuindo com sua responsabilidade de proporcionar uma educação com melhor qualidade e melhoria de vida aos sujeitos.

Pode-se analisar também, no mesmo contexto, a questão das TIC's, pois como a sociedade exige a preparação dos sujeitos para se relacionarem com as TIC's no mercado de trabalho, normalmente a escola é obrigada a utilizar essas tecnologias, mas recebe subsídios para essa inserção? Se reflete sobre as novas metodologias que devem ser utilizadas? Os alunos participam dessas reflexões? São questionamentos pertinentes visto que a docência não se faz apenas cumprindo normas, mas a partir de interações entre sujeitos, entre sujeitos e culturas, entre culturas e culturas e outros. Não significa que o respaldo teórico-metodológico utilizado é ruim ou excelente, mas sim que é preciso refletir sobre a docência como profissão e analisar todas as relações existentes nesse contexto.

Em suma, é importante a discussão sobre os princípios da instituição escolar e a relação destes com as TICs, pois quando o docente se apropria destas informações, ele compreende sua função enquanto educador, além da função social da escola. Saber que a educação não é apenas um serviço faz com que não haja limites de possibilidades de aprendizagem. A democracia se torna ferramenta essencial para quebrar as barreiras impostas por uma educação extremamente tradicional, engessada, arraigada que se perpetua até o presente momento. A instituição escolar precisa possibilitar meios para as gerações futuras modificarem uma dada realidade, mas para isso, precisa saber quais ferramentas que darão suporte a esse novo modelo de aprendizagem, levando em consideração a cotidianidade e a interação dos sujeitos envolvidos no processo educacional.

É fundamental quebrar barreiras de compreensão, historicamente construída, sobre a profissão docente como algo secundário, e não como um trabalho, uma profissão. Entender a docência como trabalho, trará mudanças significativas desde questões macros, como políticas públicas, até questões micros, mas não menos importante, como a metodologia utilizada em sala de aula. Assim, é indispensável discutir desde questões de trabalho, questões mais práticas/concretas até questões mais subjetivas sobre a profissão docente e sua relação com as TICs, pois a escola atende as necessidades sociais vigentes e para isso precisa refletir sua prática constantemente. 


\section{REFERÊNCIAS BIBLIOGRÁFICAS}

BACHELARD, G. A formação do espírito científico. Rio de Janeiro: Contraponto, 1996. BRASIL. Lei $\mathrm{n}^{\circ}$ 9394, 20 de dezembro de 1996. Estabelece as diretrizes e bases da educação nacional. Diário oficial da União. Brasília, DF, 23 dez. 1996. DF: 1997.

Parâmetros Curriculares Nacionais: 3 e 4 ciclos, Ensino Médio. Brasília:

FOUCAULT, M. A Arqueologia do saber. Rio de Janeiro: Forense Universitária, 2013. A ordem do discurso. São Paulo: Editora Loyola, 2010.

Microfísica do poder. Rio de Janeiro: Edições Graal, 1979.

FRIGOTTO, G. A produtividade da escola improdutiva. São Paulo: Cortez, 1984.

HELlER, Agnes. O Cotidiano e a história. São Paulo: Paz e Terra, 2004. $7^{\text {a }}$ ed.

LIMA, Leandro Holanda Fernandes de, MOURA, Flavia Ribeiro de. O professor no ensino híbrido. In: BACICH, Lilian, NETO, Adolfo Tanzi e TREVISANI, Fernando Mello. Ensino Híbrido: personalização e tecnologia na educação. Porto Alegre: Penso, 2015. p. $90-102$.

MEIRIEU, Philippe. O cotidiano da escola e da sala de aula: o fazer e o compreender. Porto Alegre: Armed, 2005.

MORAN, José Manoel. MACETTO, Marcos T. BEHRENS, Marilda Aparecida. Novas tecnologias e mediação pedagógica. 19. ed. Campinas, SP. Papirus, 2007.

Educação híbrida: um conceito-chave para a educação, hoje. In: BACICH, Lilian, NETO, Adolfo Tanzi e TREVISANI, Fernando Mello. Ensino Híbrido: personalização e tecnologia na educação. Porto Alegre: Penso, 2015. p. 27-45

SAVIANI, Demerval. Pedagogia histórico crítica. Campinas, SP: Autores Associados, 2013. 